Check for updates

Cite this: RSC Adv., 2019, 9, 5002

\title{
Browning control of fresh-cut Chinese yam by edible coatings enriched with an inclusion complex containing star anise essential oil
}

\begin{abstract}
Guangjie Zhang, (D) ab Lingbiao Gu, ${ }^{\mathrm{b}}$ Zhifang Lu, ${ }^{\mathrm{b}}$ Chao Yuan*cd and Yonghai Sun*a
Star anise essential oil (SAEO) has a variety of antioxygenic and antimicrobial properties, and is widely used in food preservation. However, its application is still challenging due to poor water solubility and physicochemical stability. We now report that encapsulation of SAEO in hydroxypropyl- $\beta$-cyclodextrin (HPCD) enhances its water solubility, as well as its thermal, storage, and photostability. The solubility of SAEO encapsulated by HPCD was increased by 47.5 times at $45^{\circ} \mathrm{C}$, and the onset temperature of thermal volatilization was delayed by at least $200{ }^{\circ} \mathrm{C}$. The encapsulated material is also more uniformly and more stably dispersed in xanthan gum, and is thus released in a controlled manner. Importantly, fresh-cut Chinese yam coated with xanthan gum containing encapsulated SAEO is more effectively preserved, as assessed using weight loss, $L^{*}$ value, browning index, and polyphenol oxidase activity. The data suggest that the encapsulated SAEO reduced the weight loss of the samples by more than $30 \%$, and the encapsulation of HPCD increased the inhibitory effect of SAEO on browning and polyphenol oxidase activity of the samples by nearly 8 times and more than 7 times, respectively. Collectively, SAEO encapsulated in HPCD is promising as a preservative coat for fresh-cut fruits and vegetables.
\end{abstract}

Received 8th October 2018

Accepted 1st February 2019

DOI: $10.1039 / c 8 \mathrm{ra0} 8295 b$

rsc.li/rsc-advances such as trimming, peeling, grading, and shredding may accelerate deterioration, weight loss, browning, and even loss of nutrients. ${ }^{14}$ Thus, minimizing chemical and biological changes during storage is critical. Traditional preservation methods include application of chemical additives such as chlorine, although consumers also prefer fruits and vegetables that are free of chemical residues, since such residues are potentially harmful to humans and the environment. Accordingly, several natural antimicrobials such as plant essential oils have been investigated as alternative.

These natural antimicrobials can be infused into edible coatings, which have also attracted attention for simplicity of use and eco-friendliness. As semi-permeable barriers, edible coatings can prevent water loss, gas exchange, and oxidation, and act as carriers for active components such as essential oils. At present, xanthan gum is the most widely used as edible coating due to unique characteristics. For example, it forms a highly viscous solution in cold or hot water even at low concentration, is stable over a wide range of $\mathrm{pH}$ and temperature, and is resistant to enzymatic degradation. ${ }^{15}$ Accordingly, xanthan gum enriched with active components has been tested on minimally processed fresh-cut fruits and vegetables. ${ }^{\mathbf{1 6 , 1 7}}$ However, a coating for fresh-cut yam has been limited mostly to chitosan and chitosan infused with essential oil. ${ }^{18}$ Indeed, there is little or no literature to our knowledge describing the use of xanthan gum infused with cyclodextrin-encapsulated SAEO as preservative for fresh-cut Chinese yams. Hence, we investigated the water solubility and stability of SAEO encapsulated in 
HPCD, as well as its effect on weight loss, $L^{*}$ value, browning index, and polyphenol oxidase activity of fresh-cut Chinese yam when incorporated into edible coatings based on xanthan gum. We note that in China, yam is not only commonly regarded as a tonic food, but also has been used for more than 2000 years as traditional treatment against diabetes, diarrhoea, asthma, and other ailments. ${ }^{19}$

\section{Materials and methods}

\section{Materials}

Star anise and Chinese yam (Huai Shan Yao) were purchased from Dennis Supermarket in Anyang City, Henan Province, China. Samples were transported to the laboratory and stored at $5{ }^{\circ} \mathrm{C}$ overnight before processing. SAEO was obtained by hydrodistillation, and was dried with anhydrous sodium sulphate. HPCD (purity $>99 \%$, average $M_{\mathrm{w}}=1380$ ) was obtained from Sigma-Aldrich Shanghai Trading Co. Ltd. (Shanghai, China), while xanthan gum was procured from Shandong Xiya Chemical Industry Co., Ltd. All other reagents were analytical grade. The water used in all experiments was doubly distilled and deionized.

\section{Preparation of SAEO/HPCD}

SAEO/HPCD was prepared according to Zhang et al. ${ }^{19,20}$ Briefly, SAEO was added at molar ratio $1: 1$ to $25 \mathrm{~mL}$ of an aqueous solution of $5 \% \mathrm{~m} / \mathrm{v}$ HPCD. The mixture was then homogenized by ultrasonication for $5 \mathrm{~min}$, and magnetically stirred for $96 \mathrm{~h}$ at $30{ }^{\circ} \mathrm{C}$ in the dark. Subsequently, uncomplexed SAEO was removed by filtration at $0.45 \mu \mathrm{m}$ to obtain pure SAEO/HCPD complex. Finally, filtrates were lyophilized at $-60{ }^{\circ} \mathrm{C}$ and 100 $\mathrm{Pa}$ in a Millrock Technology BT85 freeze dryer (Millrock Technology, Inc., Kingston, New York, USA).

\section{Water solubility and stability of encapsulated SAEO}

Morphology. The morphology of HPCD and SAEO/HCPD was assessed at $40 \times$ on a BT-1600 Image Particle Analysis System (Better, Dandong, Liaoning, China), and on an HT7700 transmission electron microscope (Hitachi, Tokyo, Japan) operating at accelerating voltage $80 \mathrm{kV}$. Briefly, particles were spotted on $0.085 \mathrm{~mm}$ copper grids and air dried before imaging.

Water solubility. The solubility of SAEO/HCPD in water was assessed according to Yuan et al. ${ }^{21}$ In brief, excess SAEO was added to $25 \mathrm{~mL}$ of aqueous HPCD (0-40 $\left.\mathrm{mmol} \mathrm{L}^{-1}\right)$ and magnetically stirred at 25,35 , and $45{ }^{\circ} \mathrm{C}$ for $96 \mathrm{~h}$, respectively. Uncomplexed SAEO was removed by filtration at $0.45 \mu \mathrm{m}$ to obtain pure SAEO/HCPD complex. A sample $(10 \mathrm{~mL})$ of the resulting filtrate was added to $20 \mathrm{~mL} n$-hexane and extracted by ultrasonication for $10 \mathrm{~min}$. The absorbance of the extract was determined at $258 \mathrm{~nm}$, and the concentration of SAEO was calculated according to a standard curve. Phase solubility curves were constructed by plotting $\mathrm{mmol} \mathrm{L}^{-1}$ HPCD as abscissa and mmol $\mathrm{L}^{-1}$ SAEO as ordinate. The stability constant $K_{\mathrm{C}}(\mathrm{L}$ $\mathrm{mol}^{-1}$ ) for SAEO/HCPD was determined in triplicate according to

$$
K_{\mathrm{C}}=\frac{10^{3} k}{S_{0}(1-k)}
$$

where $S_{0}\left(\mathrm{mmol} \mathrm{L}^{-1}\right)$ is the inherent solubility of SAEO in deionized water and $k$ is the slope of the linear equation. The thermodynamic properties of the complex were estimated from the experimentally determined $K_{\mathrm{C}}$ values, using eqn (2) and (3).

$$
\begin{gathered}
\Delta G=\Delta H-T \Delta S=-R T \ln K \\
\ln K_{\mathrm{C}}=-\frac{\Delta H}{R T}+\frac{\Delta S}{R}
\end{gathered}
$$

where $\Delta G\left(\mathrm{~J} \mathrm{~mol}^{-1}\right)$ is the Gibbs free energy, $\Delta H\left(\mathrm{~J} \mathrm{~mol}^{-1}\right)$ is the change in enthalpy, $R$ is the gas constant with value $8.31 \mathrm{~J}\left(\mathrm{~K}^{-1}\right.$ $\left.\mathrm{mol}^{-1}\right), T(\mathrm{~K})$ is the absolute temperature, and $\Delta S\left(\mathrm{~J}\left(\mathrm{~K}^{-1} \mathrm{~mol}^{-1}\right)\right)$ is the change in entropy.

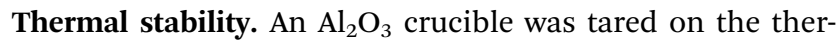
mobalance of a TA SD TQ600 TGA/DTA combined analyser (New Castle, USA), loaded with 8-15 mg SAEO, SAEO/HPCD, or HPCD. After compaction, samples were heated from $50{ }^{\circ} \mathrm{C}$ to $600{ }^{\circ} \mathrm{C}$ at $10{ }^{\circ} \mathrm{C} \min ^{-1}$ and under $10 \mathrm{~mL} \mathrm{~min}^{-1} \mathrm{~N}_{2}$.

Storage stability and photostability. SAEO/HPCD $(10 \mathrm{mg})$ was placed in six open glass bottles, and stored in a closed desiccator in the dark at $5 \pm 0.5,25 \pm 0.5$, and $45 \pm 0.5{ }^{\circ} \mathrm{C}$. A glass bottle was retrieved every $24 \mathrm{~h}$, and the concentration of remaining SAEO was measured on an ultraviolet spectrophotometer. Free SAEO was assayed in the same manner except that samples were taken every $1 \mathrm{~h}$ because of rapid volatilization. Residual SAEO (\%) was determined in triplicate experiments according to

$$
\text { Residual rate }=\frac{m_{t}}{m_{0}} \times 100
$$

where $m_{0}(\mathrm{mg})$ is the initial weight of free or encapsulated SAEO and $m_{t}(\mathrm{mg})$ is the weight of free or encapsulated SAEO at time $t$.

SAEO/HPCD samples $(10 \mathrm{mg})$ were also evenly spread on a dish, placed at room temperature under ultraviolet light, natural light, or in the dark, and residual SAEO was measured after $24 \mathrm{~h}$. Free SAEO was assayed in the same manner, except that residual SAEO was measured after $2 \mathrm{~h}$ because of rapid volatilization. Samples were tested at least three times.

\section{Effect of SAEO/HPCD on browning of fresh-cut Chinese yam}

Coating and storing of fresh-cut Chinese yam. Chinese yams of uniform shape, size, and colour and without physical damage were cleaned with potable water, peeled, and sliced using a sharp stainless steel vegetable cutter into $5 \mathrm{~mm}$ slices with average diameter about $3.5 \mathrm{~cm}$. To protect colour, specimens were then soaked for $20 \mathrm{~min}$ in $15 \mathrm{~g} \mathrm{~L}^{-1}$ citric acid, $1 \mathrm{~g} \mathrm{~L}^{-1}$ ascorbic acid, and $1.5 \mathrm{~g} \mathrm{~L}^{-1}$ calcium chloride, and dried at room temperature. Coating was prepared by dissolving $4 \mathrm{~g} \mathrm{~L}^{-1}$ xanthan gum powder in $250 \mathrm{~mL}$ distilled water at $70{ }^{\circ} \mathrm{C}$ until the mixture became clear. The solution was then infused with $3.3 \mathrm{~g}$ $\mathrm{L}^{-1}$ free or encapsulated SAEO. Yam slices ( $125 \mathrm{~g}, 45$ slices) were then immersed for $30 \mathrm{~s}$ in $250 \mathrm{~mL}$ of distilled water (control), $4 \mathrm{~g}$ $\mathrm{L}^{-1}$ xanthan gum, and $4 \mathrm{~g} \mathrm{~L}^{-1}$ xanthan gum with $3.3 \mathrm{~g} \mathrm{~L}^{-1}$ free SAEO or $165 \mathrm{~g} \mathrm{~L}^{-1} \mathrm{SAEO} / \mathrm{HPCD}$, which contains $3.3 \mathrm{~g} \mathrm{~L}^{-1} \mathrm{SAEO}$, 
as calculated from encapsulation efficiency. After drying at room temperature for $30 \mathrm{~min}$, slices were wrapped in polyethylene films, and stored at $5 \pm 0.5{ }^{\circ} \mathrm{C}$ in the dark for $8 \mathrm{~d}$. Samples ( $n=3$ slices per treatment) were tested on days $0,2,4$, 6 , and 8 for weight loss, lightness $\left(L^{*}\right)$, browning, and polyphenol oxidase activity. Each test was performed in triplicate.

Weight loss. Weight loss was measured gravimetrically and reported as percentage of the initial weight.

$L^{*}$ value and browning index. From a maximum of five readings, colour was measured as $L^{*}$ on an NS800 colorimeter (3NH, Shenzhen, China), following Sharma et al., ${ }^{22}$ with some modification. As initial $L^{*}$ values differed significantly due to individual differences in slices, change in $L^{*}$ value was used instead as the index of colour stability.

Browning was assessed according to Kim et al. ${ }^{23}$ In brief, $2 \mathrm{~g}$ samples were homogenized in $20 \mathrm{~mL}$ of cool distilled water and centrifuged at $11180 \times g$ and $4{ }^{\circ} \mathrm{C}$ for $5 \mathrm{~min}$. The absorbance of the resulting supernatant was measured at $410 \mathrm{~nm}$ on a Pgeneral TU-1810 spectrophotometer (Beijing, China). The browning index was calculated by multiplying the absorbance at $410 \mathrm{~nm}$ by 10 .

Polyphenol oxidase activity. Polyphenol activity in $U$ ( $g$ $\min )^{-1}$ was quantified according to Chen et al. ${ }^{24}$ with some modification. Briefly, samples ( $2 \mathrm{~g}$ ) were homogenized in $20 \mathrm{~mL}$ of $0.1 \mathrm{M}$ ice-cooled sodium phosphate buffer $\mathrm{pH} 6.5$, centrifuged for $5 \mathrm{~min}$ at $11180 \times g$ and $4{ }^{\circ} \mathrm{C}$, and $1 \mathrm{~mL}$ of the resulting supernatant was assayed with $1.5 \mathrm{~mL}$ of $0.1 \mathrm{~mol} \mathrm{~L}^{-1}$ catechol, and $2.5 \mathrm{~mL}$ of $0.1 \mathrm{M}$ sodium phosphate buffer $\mathrm{pH}$ 6.5. Enzyme activity was measured every $30 \mathrm{~s}$ for $3 \mathrm{~min}$ by absorbance at $420 \mathrm{~nm}$. One unit of enzyme activity was defined as an increase in absorbance of $0.001 \mathrm{~min}^{-1}$. Enzyme activity is reported as units of enzyme per mg protein.

\section{Results and discussion}

\section{Morphology}

The hydrophobic cavity in HPCD can accommodate various kinds of guest molecules, resulting in complexes with different morphology. As shown in Fig. 1A-1 and A-2, HPCD undergoes drastic changes in shape after encapsulating SAEO. Indeed, free HPCD particles appear as shrunken spheres, in line with the latest reports, ${ }^{25,26}$ whereas SAEO/HPCD complexes are irregular transparent sheets.

Transmission electron micrographs taken at $700 \times$ revealed that free HPCD (Fig. 1B-1) are homogeneous and spherical, while SAEO/HPCD complexes are aggregated irregular spheres of increasing size due to lack of significant net charge and electrostatic repulsion. ${ }^{27}$ The change in morphology and subsequent aggregation upon SAEO/HPCD complexation suggests an amorphous product with a single compound in the complex, i.e., an inclusion complex. ${ }^{28}$ However, aggregation does not favour release of guest molecules.

\section{Water solubility}

Phase solubility curves at 25,35 , and $45{ }^{\circ} \mathrm{C}$ are presented in Fig. 2 for SAEO and HPCD. The solubility curves for SAEO are $A_{L}$

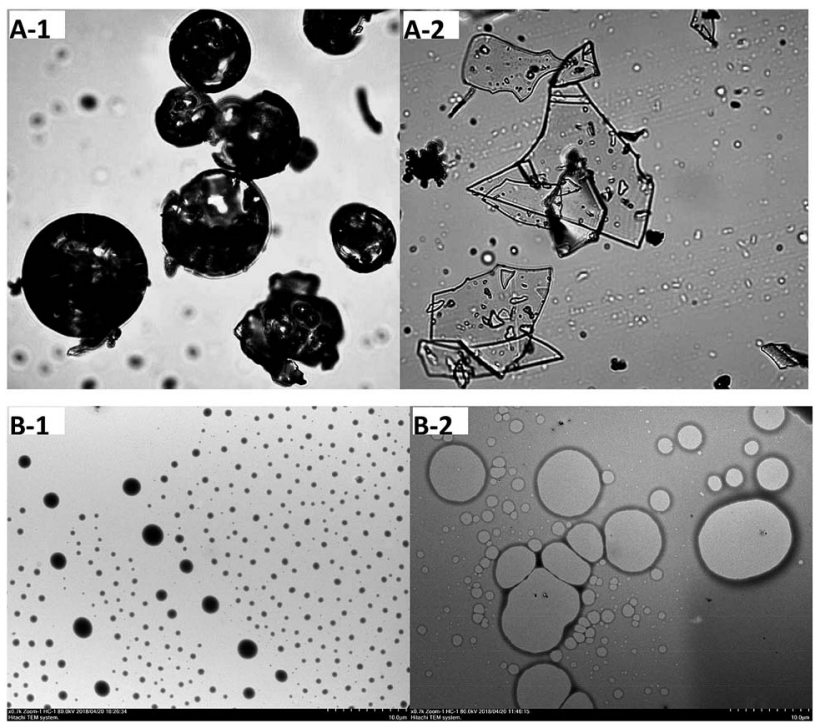

Fig. 1 Optical microscopy (OM) $(40 \times)((A-1)$ HPCD; (A-2) inclusion complex) and TEM micrographs (700x) ((B-1) HPCD; (B-2) inclusion complex) of HPCD and SAEO/HPCD inclusion complex.

type, as defined by Higuchi et al. ${ }^{29}$ The linear relationship $\left(R^{2}>\right.$ 0.99 ) between SAEO and HPCD suggest formation of a $1: 1$ SAEO/HPCD inclusion complex, in agreement with phase solubility data for trans-anethole in HPCD. ${ }^{30}$ trans-Anethole is the main component in SAEO. We estimated that encapsulation in $40 \mathrm{mmol} \mathrm{L}^{-1}$ HPCD increases the solubility of SAEO by 22.2 , 26.5 , and 47.5 -fold at $25,35,45{ }^{\circ} \mathrm{C}$, respectively. This result also indicates that the solubility of SAEO in water increases with temperature. Notably, phase solubility constants $\left(K_{\mathrm{C}}\right)$ also increased with temperature (Fig. 2), implying that SAEO/HPCD complexation is endothermic, in contrast to encapsulation of other molecules in $\beta$-cyclodextrin or HPCD. ${ }^{31,32}$ We calculated the stability constant to be $724.4716 \mathrm{~L} \mathrm{~mol}^{-1}$ at $25{ }^{\circ} \mathrm{C}$, which is lower than previously reported for trans-anethole encapsulated in $\beta$-cyclodextrin $\left(1195 \mathrm{~L} \mathrm{~mol}^{-1}\right)$ and $\operatorname{HPCD}\left(1510 \mathrm{~L} \mathrm{~mol}^{-1}\right){ }^{\mathbf{1 0 , 3 0}}$ This may be due to differences in concentrations tested during phase solubility studies, or to the higher structural complexity of SAEO, which may result in weaker interaction between SAEO and HPCD than between trans-anethole and HPCD.

Positive enthalpy values confirmed that complex formation is endothermic (Fig. 2). According to the second law of thermodynamics, a hydrophobic guest molecule will shed its water shell and release water from HPCD before entering the cavity, resulting in a gain in entropy $(\Delta S>0)$. This process is also endothermic, although the subsequent van der Waals interaction and intermolecular hydrogen bonding between the guest molecule and the inner wall of the HPCD cavity is exothermic. Hence, it is possible that the heat absorbed due to the gain in entropy is greater than the heat released by host-guest complexation, resulting in a gain in enthalpy. On the other hand, negative Gibbs free energy values indicate that complexation is spontaneous. ${ }^{33}$ The magnitude of $\Delta G$ also increased with temperature, indicating that heat promotes spontaneous complexation. As heat also boosts entropy, the data imply that 


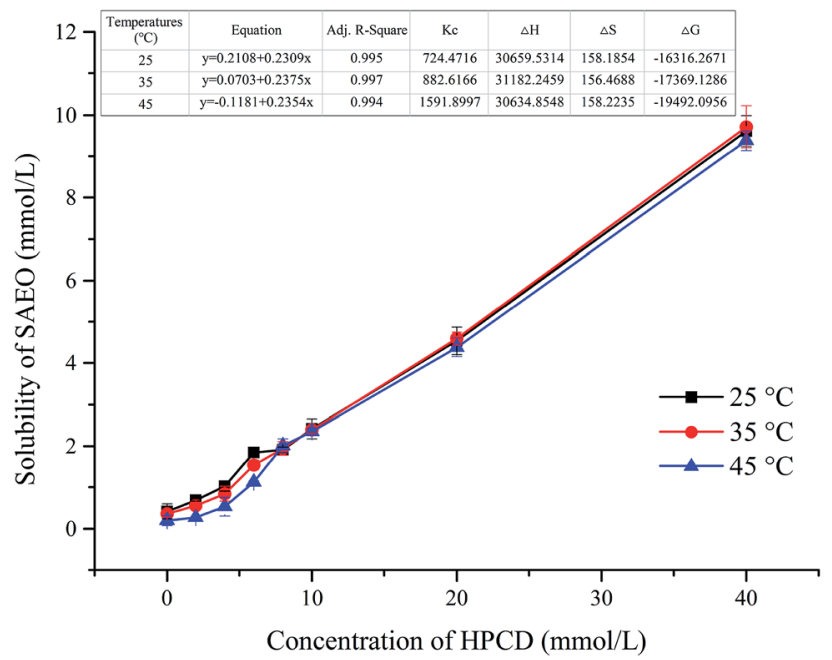

Fig. 2 Phase solubility curves and thermodynamic properties of SAEO with HPCD in water at different temperatures.

increased entropy is the main driver of complexation between SAEO and HPCD. These results also provide more evidence that inclusion complexes were created, and that encapsulation greatly enhances the solubility of SAEO in water. The increase in water solubility may favour steady release of SAEO into buffer.

\section{Thermal stability}

Since the SAEO used in this study is liquid at room temperature, its complexation with HPCD was further confirmed, albeit indirectly, by thermogravimetry and differential scanning calorimetry of the free and encapsulated forms. ${ }^{34-36}$ An indistinct, broad endothermic peak near $100{ }^{\circ} \mathrm{C}$ was observed on differential scanning calorimetry of SAEO (Fig. 3A). A slight weight loss was also observed by thermogravimetry at this point, implying that this peak is due to evaporation of a small amount of residual moisture and volatilization of SAEO. However, weight loss became pronounced above $100{ }^{\circ} \mathrm{C}$,

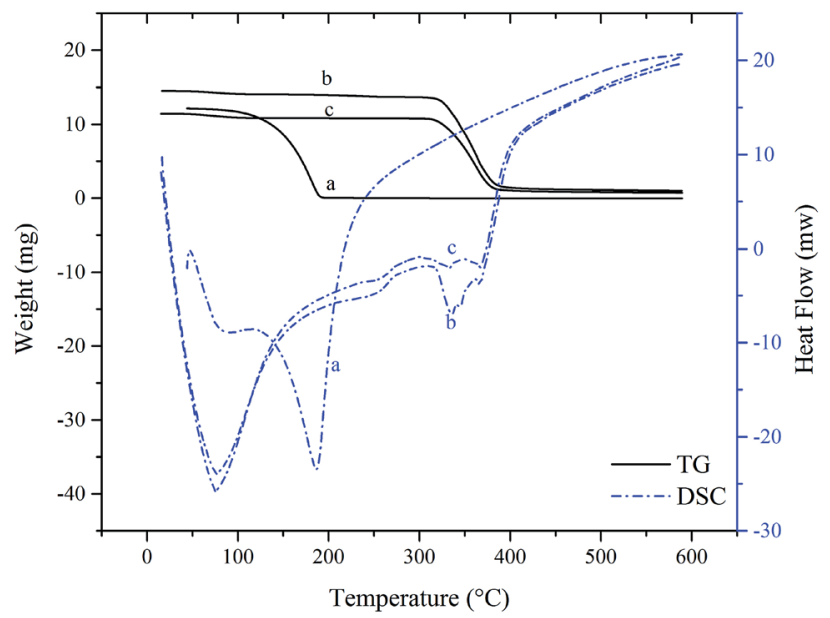

Fig. 3 TG/DSC curves of SAEO (a), inclusion complex (b) and HPCD (c). indicating volatilization of SAEO, which is indeed obtained by steam distillation. Volatilization was complete at about $197^{\circ} \mathrm{C}$, with a sharp endothermic peak at about $186^{\circ} \mathrm{C}$, suggesting that the thermal properties of SAEO are similar to those of transanethole. ${ }^{10}$ Nevertheless, the endothermic peak at $197{ }^{\circ} \mathrm{C}$ is different from the endothermic peak observed in trans-anethole,$^{30}$ presumably because of differences in heating rate among studies or because of the more complex structure of SAEO.

The thermogravimetric curve of the SAEO/HPCD inclusion complex exhibited one-step decomposition, starting at about $315{ }^{\circ} \mathrm{C}$ and ending at about $400{ }^{\circ} \mathrm{C}$. In the corresponding differential scanning calorimetry curve, a new endothermic peak was observed at about $345{ }^{\circ} \mathrm{C}$ in addition to the three endothermic peaks characteristic of HPCD, further confirming that an inclusion complex was formed. Comparison of all thermogravimetry curves indicated that formation of inclusion complexes delayed the onset of SAEO volatilization by at least $200{ }^{\circ} \mathrm{C}$ due to the stabilizing effects of HPCD. Conversely, the onset of HPCD thermal decomposition was also slightly shifted, suggesting that SAEO also stabilizes HPCD.

\section{Storage stability and photostability}

SAEO is strongly volatile, which causes not only loss of some active components but also poor storage performance. As formation of an inclusion complex can slow the release of guest molecules and reduce volatility, ${ }^{37,38}$ encapsulating SAEO in HPCD may greatly improve storage stability. Indeed, we found that encapsulated SAEO is significantly more stable than free SAEO, as measured for $144 \mathrm{~h}$ at 5, 25, and $45{ }^{\circ} \mathrm{C}$ (Fig. 4A). However, the stability of both free and encapsulated SAEO decreased with increasing temperature, such that residual free SAEO is close to 0 after $6 \mathrm{~h}$ at $45{ }^{\circ} \mathrm{C}$, but less than $40 \%$ at $5{ }^{\circ} \mathrm{C}$. Importantly, more than $80 \%$ of encapsulated SAEO in powdered form persisted after $144 \mathrm{~h}$, even exceeding $94 \%$ at $5{ }^{\circ} \mathrm{C}$. This result confirms that encapsulation stabilizes SAEO, and preserves fragrance for a long time. Moreover, encapsulation may minimize the unpleasant smell of SAEO and preserve its biological activity in aqueous solutions, presumably as a result of steric hindrance in the HPCD torus. ${ }^{39}$ In any case, the stability of the inclusion complex is also temperature-dependent.

As shown in Fig. 4B, significant loss of free SAEO was observed after $2 \mathrm{~h}$ at room temperature. Similarly, remaining SAEO under UV and natural light was only about $40 \%$ and $30 \%$ of SAEO remaining when left in the dark, indicating that both are destructive against free SAEO, as previously noted. ${ }^{40}$ We note that in sweet fennel oil stored for 2 months at room temperature under light, trans-anethole is completely transformed to anisaldehyde and cis-anethole through oxidation and isomerization, respectively. ${ }^{41}$ Light may also induce formation of 4,4'dimethoxystilbene, which is thought to result from a photocycloaddition reaction between anethole and anisaldehyde. ${ }^{\mathbf{4 2}}$ Therefore, storing free SAEO in the dark is more advantageous. On the other hand, SAEO encapsulated in HPCD is noticeably more photostable than free SAEO. Although UV light was also destructive against encapsulated SAEO, preserving only $82.9 \%$ in comparison to SEAO stored in the dark, encapsulated SAEO 


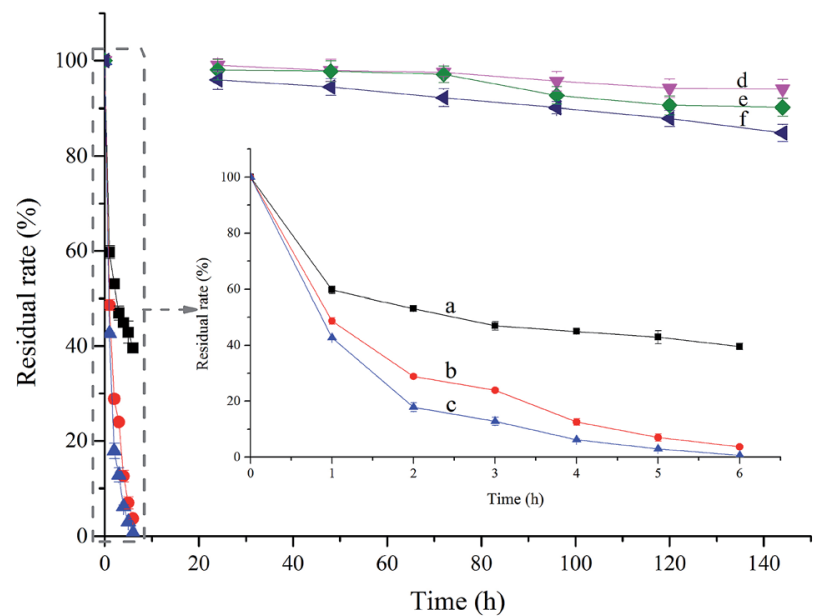

(A)

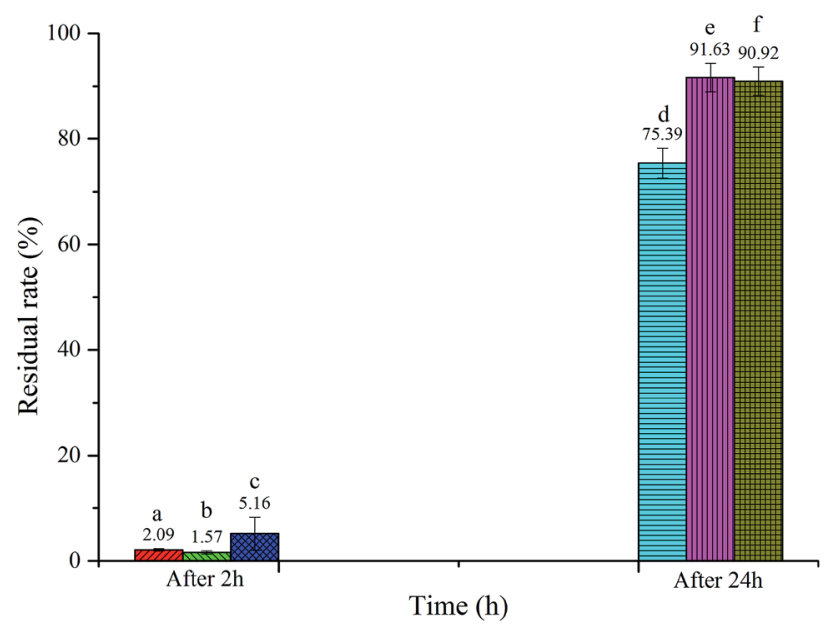

(B)

Fig. 4 Storage stability ((A) a-SAEO $/ 5{ }^{\circ} \mathrm{C}$; b-SAEO/25 ${ }^{\circ} \mathrm{C}$; c-SAEO/ $45{ }^{\circ} \mathrm{C}$; d-inclusion $/ 5{ }^{\circ} \mathrm{C}$; e-inclusion $/ 25^{\circ} \mathrm{C}$; f-inclusion $/ 45^{\circ} \mathrm{C}$ ) and photostability ((B) a-UV/SAEO; b-natural light/SAEO; c-dark/SAEO; $d$ UV/inclusion complex; e-natural light/inclusion complex; f-dark/ inclusion complex) of SAEO and inclusion complex.

was clearly stable in natural light, with $100.8 \%$ of material persisting in comparison to SAEO stored in the dark. Therefore, encapsulation improves the photostability of SAEO, and thus may improve its value in preserving fruits and vegetables.

\section{Effect of HPCD-encapsulated SAEO on browning of fresh-cut Chinese yam}

Weight loss in fresh-cut fruits and vegetables is mainly attributed to respiration, transpiration, and loss of water due to slicing. ${ }^{43}$ As seen in Fig. 5A, weight loss in fresh-cut Chinese yam increased with storage time, regardless of treatment. However, coating with xanthan gum, or with xanthan gum infused with free or encapsulated SAEO, reduced the weight loss by more than $30 \%$. The stabilizing effect of xanthan infused with encapsulated SAEO is slightly, but not significantly better than that of pure xanthan gum and xanthan gum infused with free SAEO $(p>0.05)$.
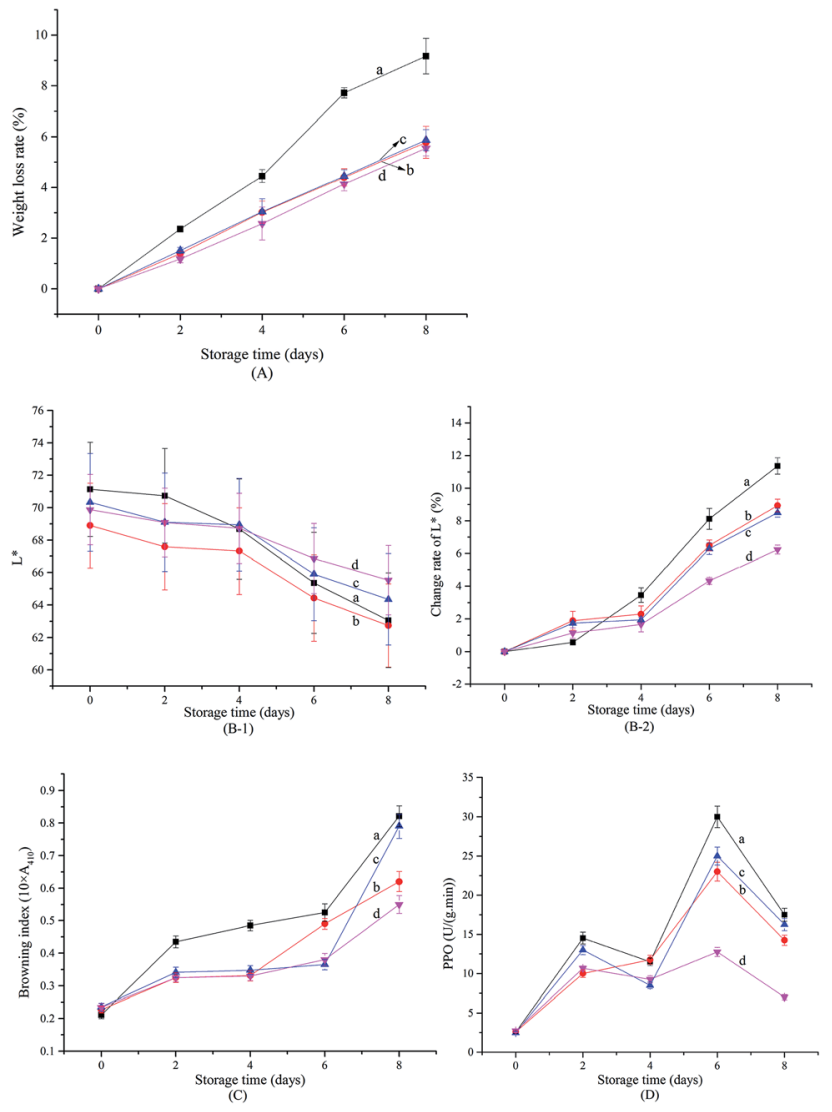

Fig. 5 Effects of various treatments on weight loss (A), $L *((B-1)$ and (B2)), browning (C) and activities of PPO (D) in fresh-cut Chinese yam stored at $5 \pm 0.5^{\circ} \mathrm{C}$ for 8 days (a: control; b: treatment with xanthan gum; c: treatment with xanthan gum containing free SAEO; d: treatment with xanthan gum containing encapsulated SAEO).

Browning at cut edges is often the main defect in fresh-cut Chinese yam. Browning is assessed by measuring lightness $\left(L^{*}\right)$ and calculating the browning index, with lower $L^{*}$ values and higher browning index indicating worse browning. As shown in Fig. 5B-1, B-2, and C, fresh-cut Chinese yam gradually browned over 8 days regardless of treatments. In particular, noticeable changes in $L^{*}$ value were observed on day 2 of storage in slices treated with distilled water, indicating accelerated browning. In comparison, browning indices were markedly lower in slices treated with xanthan gum or xanthan gum with free or encapsulated SAEO, beginning at day 2. Browning at day 6 was also less pronounced in slices treated with xanthan gum infused with free or encapsulated SAEO. Finally, browning at days 6-8 was less pronounced in slices treated with xanthan gum containing encapsulated SAEO than in slices treated with xanthan gum containing free SAEO. Especially on the 8th day, the browning indexes in slices treated with xanthan gum containing free and encapsulated SAEO were reduced by $3.7 \%$ and $32.9 \%$ compared with control, respectively, indicating that the encapsulation of HPCD enhanced the inhibition effect of SAEO on the browning of fresh-cut Chinese yam by nearly 8 times. In general, changes in $L^{*}$ value were lowest in slices treated with xanthan gum containing encapsulated SAEO. The protective 
effects of xanthan gum are attributed to preventing oxidation, the main process driving browning. On the other hand, SAEO contribute additional antioxidant effects, although water insolubility and uneven dispersion into xanthan gum may minimize synergism. However, encapsulation in HPCD efficiently improves the water solubility of SAEO and slows its release, promoting uniform dispersion into xanthan gum. Conversely, xanthan gum facilitates the suspension of particulates, ${ }^{15}$ further ensuring uniform dispersion of SAEO/HPCD, as well as long-term release of SAEO. Accordingly, xanthan gum infused with encapsulated SAEO is more effective against browning in fresh-cut Chinese yam.

Polyphenol oxidase oxidizes phenolic compounds into quinones, which subsequently form brown pigments. ${ }^{44}$ As shown in Fig. 5D, polyphenol oxidase activity in all samples increased over the first two days, slightly decreased at days 2-4, accumulated again at days 4-6, and diminished again at days 68. These changes are attributed to accumulation of the enzyme, to contact between the enzyme and its substrate, or to changes in phenylalanine ammonia lyase activity. ${ }^{45}$ The data are consistent with those from fresh-cut Artemisia selengensis, lettuce, and pears. ${ }^{22,24}$ Strikingly, polyphenol oxidase activity was significantly lower in slices treated with xanthan gum containing encapsulated SAEO than in all other specimens $(p<$ 0.05 ) beginning at day 4 , and on the 8th day, its activity was reduced by $60.0 \%$ compared with control, while similar index in slices treated with xanthan gum containing free SAEO is $7.1 \%$, suggesting that the encapsulation of HPCD enhanced the inhibition effect of SAEO on browning due to polyphenol oxidase activity by more than 7 times. As noted, this effect may be due to the function of xanthan gum as oxygen barrier and its reinforcement by SAEO/HPCD. ${ }^{17,46}$

\section{Conclusions}

The data confirm that encapsulation in HPCD enhances the water solubility of SAEO by 47.5 -fold at $45{ }^{\circ} \mathrm{C}$, as well as its storage and photostability. Indeed, while SAEO/HPCD tends to aggregate, as observed on electron microscopy, xanthan gum promotes its suspension, uniform dispersion, and controlled long-term release. Phase solubility studies also showed that SAEO is effectively encapsulated in HPCD to form an inclusion complex with molar ratio $1: 1$. On the other hand, thermodynamic parameters indicated that the formation of this complex is endothermic and accelerated by heat. Further, thermogravimetry and differential scanning calorimetry suggested that encapsulation delays the volatilization of SAEO by more than $200{ }^{\circ} \mathrm{C}$. Finally, encapsulated SAEO inhibits browning in freshcut Chinese yam when added to edible coatings based on xanthan gum, as assessed by weight loss, $L^{*}$ value, browning index, and polyphenol oxidase activity. The results show that the encapsulated SAEO reduced the weight loss of the samples by more than $30 \%$, and the encapsulation of HPCD increased the inhibitory effect of SAEO on browning and polyphenol oxidase activity of the samples by nearly 8 times and more than 7 times, respectively. Thus, SAEO/HPCD is promising as coating for fresh-cut fruits and vegetables.

\section{Conflicts of interest}

There are no conflicts to declare.

\section{Acknowledgements}

This work was supported by National Natural Science Foundation of China $(31571881,31271861)$ and Henan Science and Technology Tackling Key Project (172102110003).

\section{References}

1 A. Padmashree, N. Roopa, A. D. Semwal, G. K. Sharma, G. Agathian and A. S. Bawa, Food Chem., 2007, 104(1), 59-66.

2 C. K. George, Handbook of Herbs and Spices, Woodhead Publishing, 2nd edn, 2012, pp. 487-503.

3 G. Singh, S. Maurya, M. P. DeLampasona and C. Catalan, J. Sci. Food Agric., 2006, 86(1), 111-121.

4 L. Higueras, G. López-Carballo, P. Hernández-Muñoz, R. Catalá and R. Gavara, Int. J. Food Microbiol., 2014, 188C, 53-59.

5 R. L. Abarca, F. J. Rodríguez, A. Guarda, M. J. Galotto and J. Bruna, Food Chem., 2016, 196(4), 968-975.

6 P. Wen, D. H. Zhu, H. Wu, M. H. Zong, Y. R. Jing and S. Y. Han, Food Control, 2016, 59, 366-376.

7 A. Ciobanu, I. Mallard, D. Landy, G. Brabie and D. Nistor, Food Chem., 2013, 138(1), 291-297.

8 M. Kfoury, N. G. Hădărugă and D. I. Hădărugă, Encapsulations, 2016, 127-192.

9 M. Kfoury, L. Auezova and H. L. N. Greige-Gerges, Carbohydr. Polym., 2015, 131, 264-272.

10 W. Zhang, X. Li, T. Yu, L. Yuan, G. Rao, D. Li and C. Mu, Food Res. Int., 2015, 74, 55-62.

11 P. C. Costa, B. Medronho, S. Gon Alves and A. Romano, Ind. Crops Prod., 2015, 70, 341-346.

12 H. Liu, G. Yang, Y. Tang, D. Cao, T. Qi, Y. Qi and G. Fan, Int. J. Pharm., 2013, 450(1-2), 304-310.

13 M. A. Donegá, M. A. Tessmer, E. D. Mooz, L. T. Dall'Orto, F. F. Sasaki and R. A. Kluge, Hortic. Bras., 2013, 31(31), 248-254.

14 A. B. Martín-Diana, D. Rico and C. Barry-Ryan, Innovative Food Sci. Emerging Technol., 2008, 9(4), 593-603.

15 G. Sworn, Handbook of Hydrocolloids, Woodhead Publishing, 2nd edn, 2009, pp. 186-203.

16 M. L. Zambrano-Zaragoza, E. Mercado-Silva, L. A. Del Real, E. Gutiérrez-Cortez, M. A. Cornejo-Villegas and D. Quintanar-Guerrero, Innovative Food Sci. Emerging Technol., 2014, 22, 188-196.

17 M. L. Zambrano-Zaragoza, D. Quintanar-Guerrero, A. Del Real, E. Piñon-Segundo and J. F. Zambrano-Zaragoza, Carbohydr. Polym., 2017, 157, 1874-1882.

18 L. J. Wang, T. U. Qiong-Fang, Y. Liu, F. F. Qiao and Z. Y. Zhang, Sci. Technol. Food Ind., 2009, 30(4), 309-311.

19 D. Yang and J. Lin, Food Chem., 2008, 110(3), 670-677.

20 G. Zhang, C. Yuan and Y. Sun, Molecules, 2018, 23(5), 1126. 21 C. Yuan, Z. Lu and Z. Jin, Food Chem., 2014, 152, 140-145. 
22 S. Sharma and T. V. R. Rao, LWT-Food Sci. Technol., 2015, 62(1), 791-800.

23 D. Kim, H. Kim, H. Chung and K. Moon, Food Chem., 2014, 159, 188-192.

24 X. Chen, L. Ren, M. Li, J. Qian, J. Fan and B. Du, Food Chem., 2017, 214, 432-439.

25 Y. Wei, J. Zhang, Y. Zhou, W. Bei, Y. Li, Q. Yuan and H. Liang, Carbohydr. Polym., 2017, 159, 152-160.

26 Q. Li, H. Pu, P. Tang, B. Tang, Q. Sun and H. Li, Food Chem., 2018, 245, 1062-1069.

27 L. E. Hill, C. Gomes and T. M. Taylor, LWT-Food Sci. Technol., 2013, 51(1), 86-93.

28 R. Chauhan, J. Madan, D. Kaushik, S. Sardana, R. S. Pandey and R. Sharma, Pharm. Dev. Technol., 2013, 18(2), 313-322.

29 T. A. Higuchi and K. A. Connors, Adv. Anal. Chem. Instrum., 1965, 117-212.

30 M. Kfoury, L. Auezova, H. L. N. Greige-Gerges, S. Ruellan and S. Fourmentin, Food Chem., 2014, 164, 454-461.

31 F. Tao, L. E. Hill, Y. Peng and C. L. Gomes, LWT-Food Sci. Technol., 2014, 59(1), 247-255.

32 J. Rakmai, B. Cheirsilp, J. C. Mejuto, A. Torrado-Agrasar and J. S. Simal-G Ndara, Food Hydrocolloids, 2017, 65, 157-164.

33 V. T. Karathanos, I. Mourtzinos, K. Yannakopoulou and N. K. Andrikopoulos, Food Chem., 2007, 101(2), 652-658.

34 H. Gao, L. Chen, W. Chen and S. Bao, Thermochim. Acta, 2013, 569, 134-138.
35 X. Wang, Z. Luo and Z. Xiao, Carbohydr. Polym., 2014, 101, 1027-1032.

36 L. Yang, S. Wang, S. Zhou, F. Zhao, Q. Chang, M. Li, W. Chen and X. Yang, Mater. Sci. Eng., C, 2017, 76, 1136-1145.

37 H. M. C. Marques, A. C. Figueiredo and M. G. Miguel, Flavour Fragrance J., 2010, 25(5), 313-326.

38 E. Pinho, M. Grootveld, G. Soares and M. Henriques, Crit. Rev. Biotechnol., 2014, 34(4), 328-337.

39 J. Wang, Y. Cao, B. Sun and C. Wang, Food Chem., 2011, 127(4), 1680-1685.

40 R. Gharib, L. Auezova, C. Charcosset and H. Greige-Gerges, Food Chem., 2017, 218, 365-371.

41 T. A. Misharina and A. N. Polshkov, Prikl. Biokhim. Mikrobiol., 2005, 41(6), 693.

42 H. Miething, V. Seger and R. Hänsel, Phytother. Res., 2010, 4(3), 121-123.

43 S. L. S. Bico, M. F. J. Raposo, R. M. S. C. Morais and A. M. M. B. Morais, Food Control, 2009, 20(5), 508-514.

44 F. A. Tomasbarberan and J. C. Espin, J. Sci. Food Agric., 2010, 81(9), 853-876.

45 T. Boller, J. Cell. Biochem., 1984, 26(suppl. 8B), 213-261.

46 M. J. Piercey, G. Mazzanti, S. M. Budge, P. J. Delaquis, A. T. Paulson and L. T. Hansen, Food Microbiol., 2012, 30(1), 213-218. 